\title{
Spatially Extended Habitat Modification by Intertidal Reef- Building Bivalves has Implications for Consumer-Resource Interactions
}

\author{
Els M. van der Zee,${ }^{1,2 *}$ Tjisse van der Heide, ${ }^{3}$ Serena Donadi, ${ }^{4}$ \\ Johan S. Eklöf, ${ }^{4}$ Britas Klemens Eriksson, ${ }^{4}$ Han Olff, ${ }^{3}$ \\ Henk W. van der Veer, ${ }^{1}$ and Theunis Piersma ${ }^{1,2}$
}

\begin{abstract}
${ }^{1}$ Department of Marine Ecology, NIOZ Royal Netherlands Institute for Sea Research, P.O. Box 59, 1790 AB Den Burg, Texel The Netherlands; ${ }^{2}$ Animal Ecology Group, Centre for Ecological and Evolutionary Studies (CEES), University of Groningen, P.O. Box 11103, 9700 CC Groningen, The Netherlands; ${ }^{3}$ Community and Conservation Ecology Group, Centre for Ecological and Evolutionary Studies (CEES), University of Groningen, P.O. Box 11103, 9700 CC Groningen, The Netherlands; ${ }^{4}$ Marine Benthic Ecology and Evolution, Centre for Ecological and Evolutionary Studies (CEES), University of Groningen, P.O. Box 11103, 9700 CC Groningen, The Netherlands
\end{abstract}

\begin{abstract}
Ecosystem engineers can strongly modify habitat structure and resource availability across space. In theory, this should alter the spatial distributions of trophically interacting species. In this article, we empirically investigated the importance of spatially extended habitat modification by reef-building bivalves in explaining the distribution of four avian predators and their benthic prey in the Wadden Sea-one of the world's largest intertidal soft-sediment ecosystems. We applied Structural Equation Modeling to identify important direct and indirect interactions between the different components of the system. We found strong spatial gradients in
\end{abstract}

Received 8 November 2011; accepted 4 March 2012; published online 4 April 2012

Electronic supplementary material: The online version of this article (doi:10.1007/s10021-012-9538-y) contains supplementary material, which is available to authorized users.

Author contributions: Els van der Zee and Tjisse van der Heide have conceived the study, performed research, analyzed the data and written the paper. Serena Donadi and Johan Eklöf have conceived the study, performed research and participated in writing the paper. Britas Klemens Eriksson, Han Olff and Henk van der Veer participated in writing the paper. Theunis Piersma participated in analyzing the data and writing the paper.

*Corresponding author; e-mail: els.vanderzee@nioz.nl sediment properties into the surrounding area of mixed blue mussel (Mytilus edulis) and Pacific oyster (Crassostrea gigas) reefs, indicating large-scale (100s of $\mathrm{m}$ ) engineering effects. The benthic community was significantly affected by these gradients, with the abundance of several important invertebrate prey species increasing with sediment organic matter and decreasing with distance to the reefs. Distance from the reef, sediment properties, and benthic food abundance simultaneously explained significant parts of the distribution of oystercatchers (Haematopus ostralegus), Eurasian curlews (Numenius arquata), and bar-tailed godwits (Limosa lapponica). The distribution of black-headed gulls (Chroicocephalus ridibundus) - a versatile species with many diet options-appeared unaffected by the reefs. These results suggest that intertidal reef builders can affect consumer-resource dynamics far beyond their own boundaries, emphasizing their importance in intertidal soft-bottom ecosystems like the Wadden Sea.

Key words: ecosystem engineer; Mytilus edulis; Crassostrea gigas; habitat modification; extended effects; spatial species distribution; benthic community; shorebirds. 


\section{INTRODUCTION}

Over the last decades it has become well established that some organisms can have disproportionally strong effects on their abiotic environment, indirectly affecting other species. Such species, often called 'ecosystem engineers' by Jones and others (1994), typically promote their own preferred conditions at the local ('patch') scale (Bertness and Leonard 1997; Rietkerk and others 2004 and references therein). However, ecosystem engineering is often not only important locally, but may also have strong impacts at landscape scales (Wright and others 2002; Kefi and others 2007; Scanlon and others 2007). Apart from altering the spatial structure of the environment, ecosystem engineers may affect the spatial distribution and abundance of their resources (for example, nutrients, water, and light). This also alters resource availability for other species (Gutierrez and others 2003; van de Koppel and others 2006), which should in turn affect the spatial distribution of their consumers (for example, Hassell and May 1974; Folmer and others 2010; Piersma 2012). Although effects of prey-patchiness and ecosystem engineering on the distribution of species have been documented separately (for example, Hassell and May 1974; Wright and others 2002), assessments of the spatially extended effects of ecosystem engineers on resources, and their consumers have remained largely theoretical (Bagdassarian and others 2007; Olff and others 2009).

Reef builders like blue mussels (Mytilus edulis) and Pacific oysters (Crassostrea gigas) are striking examples of ecosystem engineers that impact their environment through habitat modification (Kröncke 1996; Gutierrez and others 2003; Kochmann and others 2008). At a local scale, mussels and oysters create hard substrate and increase habitat complexity, reduce hydrodynamics, and modify the sediment by depositing large amounts of pseudofeces and other fine particles (Kröncke 1996; Hild and Günther 1999; Gutierrez and others 2003). However, in soft-bottom systems, their effects on sediment conditions typically extend beyond the direct surroundings of the reefs and may be detectable up to several hundreds of meters (Kröncke 1996; Bergfeld 1999). Many studies have demonstrated that reef builders have an important effect on the local benthic community (Dittmann 1990; Norling and Kautsky 2008; Markert and others 2009) and that the reefs themselves are important foraging grounds for avian consumers (for example, Nehls and others 1997; Caldow and others 2003). However, the spatially extended effects of such reef builders on this community remain largely unstudied.

Furthermore, possible implications of such spatially extended habitat modification on the community may also be important from a management perspective. In many intertidal soft-sediment systems, like the Wadden Sea, ecosystem engineers have disappeared due to multiple anthropogenic disturbances and many associated species disappeared with them (Piersma and others 2001; Lotze and others 2005; Kraan and others 2007; Eriksson and others 2010). For instance, in the Wadden Sea, $150 \mathrm{~km}^{2}$ of seagrasses disappeared in the $1930 \mathrm{~s}$ (van der Heide and others 2007) and mussel beds were almost completely removed in the beginning of the 1990s and have only partly recovered thus far (Beukema and Cadee 1996). If spatial effects of ecosystem engineers are not recognized, such dramatic changes might result in unexpectedly strong losses in these ecosystems.

In this article, we investigate the effects of spatial habitat modification by mixed blue mussel and Pacific oyster reefs on the distribution of benthic prey and their consumers (shorebirds) at a sandy intertidal flat. We collected spatially explicit data on important abiotic variables and the biota in and around two reefs in the Dutch Wadden Sea. We used Structural Equation Modeling (SEM) to infer the relative importance of ecosystem engineering on the spatial distribution of recourses and consumers. Based on sediment and benthos data of 119 sampling stations at varying distances from the reefs and the spatial mapping of shorebirds, we constructed default models for four of the most commonly observed bird species that included all possible interactions between the birds and their environment. Next, we determined the relative importance of each interaction, using an approach with stepwise exclusion of variables.

\section{Materials AND Methods}

\section{Study Area}

Our study area covered about 44 ha of intertidal mudflats, south of the island of Schiermonnikoog in the eastern Dutch Wadden Sea $\left(53^{\circ} 28^{\prime} 15.75^{\prime \prime} \mathrm{N}\right.$, $\left.6^{\circ} 13^{\prime} 20.06^{\prime \prime} \mathrm{E}\right)$. These intertidal flats contain a variety of macrobenthic invertebrate species (Beukema 1976) that are accessible to shorebirds twice a day (van de Kam and others 2004; van Gils and others 2006). The area contained two mixed reefs of blue mussels and Pacific oysters, established in 2002 (Goudswaard and others 2007 and unpublished data of our research group). The main 
cohort of bivalves was 7 years old, with several younger cohorts. Before the establishment of the two reefs, our study area consisted of a sandy intertidal flat without patches of hard substrata (van de Pol 2006 and unpublished data of our research group). The spatial relationships of the reef builders with the local and surrounding benthic community and associated shorebirds were examined at two adjacent study areas of 22 ha each (see Figure 2).

\section{Benthic Sampling}

Sediment, pore water, and benthic samples were collected in August 2009 on a predetermined $100 \mathrm{~m}$ grid with 46 additional random points. In total, 119 station points were sampled across the two study sites. All stations were identified during low tide using a handheld GPS. At each sampling station, we sampled and pooled three $5 \mathrm{~cm}$ deep sediment cores with a PVC corer with an area of $7.1 \mathrm{~cm}^{2}$. Sediment organic matter content in dried sediment $\left(24 \mathrm{~h}, 70^{\circ} \mathrm{C}\right)$ was estimated as weight Loss On Ignition (LOI; $\left.5 \mathrm{~h}, 550^{\circ} \mathrm{C}\right)$. Silt content $(\%$ sediment fraction $<63 \mu \mathrm{m})$ was determined by a particle size analyzer (Malvern). Redox potential was measured immediately after sampling with a multi-probe meter (556 MPS, YSI) in pore water that was extracted from the sediment with a ceramic cup into a vacuumized $50 \mathrm{ml}$ syringe. Benthic samples were taken with a stainless steel core with area of $179 \mathrm{~cm}^{2}$ down to a depth of $20-25 \mathrm{~cm}$. Samples were sieved over a $1 \mathrm{~mm}$ mesh and all fauna fixed in $4 \%$ formalin. In the laboratory, samples were stained with Rose Bengal, and fauna was identified to species level. Ash free dry mass (AFDM) of each species was determined by LOI $\left(5 \mathrm{~h}, 550^{\circ} \mathrm{C}\right)$ after drying for $48 \mathrm{~h}$ in a stove at $60^{\circ} \mathrm{C}$.

\section{Bird Mapping}

A $3.2 \mathrm{~m}$ high observation platform was constructed $100 \mathrm{~m}$ away from each of the two study sites in such a way that the platforms covered the respective sampling grids, that is, a reef and the associated gradient towards a sandy area, all within a radius of $500 \mathrm{~m}$. The spatial distribution of shorebirds was determined during four tidal cycles between 18 August and 8 September 2009. Positions of individual birds were determined using the newly developed Telescope-Mounted Angulator (TMA) described by van der Heide and others (2011). This was done from an hour before to an hour after the time of low water, that is, when the areas were completely exposed and tidal movement would not affect their spatial distribution. With the TMA, using trigonometry, we were able to determine a bird's spatial position with high accuracy (maximum prediction error of $8.7 \mathrm{~m}$ at $500 \mathrm{~m}$; van der Heide and others 2011).

We mapped the spatial distribution of four common shorebird species: oystercatcher (Haematopus ostralegus), Eurasian curlew (Numenius arquata), bar-tailed godwit (Limosa lapponica), and black-headed gull (Chroicocephalus ridibundus). These focal species were chosen for three reasons. First, due to their body size, all four species are easy to follow and clearly visible, which prevented double counting and inaccurate positioning (van der Heide and others 2011). Second, all four species form sparse flocks, a feature that represents a degree of sensitivity to interference of conspecifics (Goss-Custard 1980; Piersma 1985). In contrast to social and interference-insensitive species, the distribution of such interference-sensitive species should mostly be determined by the distribution of food resources (Folmer and others 2010). Third, each of these species should differ in its degree of association with mussel and oyster reefs. For example, as blue mussels form a substantial part of their diet, oystercatchers tend to be highly associated with reef builders (Goss-Custard 1996). Eurasian curlew typically respond to an increased abundance of crabs and shrimps in and near reefs compared to sandy intertidal flats, but they also feed on bare mudflats (Goss-Custard and Jones 1976; Petersen and Exo 1999). The degree of association for bar-tailed godwits is probably lower, because they feed on a large variety of benthic animals often along the edge of the receding and advancing tide (Goss-Custard and others 1977; Scheiffarth 2001). Black-headed gulls feed on a large variety of prey and can be found in many different habitats (Dernedde 1994; Kubetzki and Garthe 2003).

\section{Data Analysis}

Both study sites were subdivided by Thiessen polygons (Thiessen 1911) in ArcGIS (Environmental Systems Research Institute, Redlands, California, USA). Each polygon defines a discrete area around each sampling station (both random and predetermined) in such a way that any location inside the polygon is closer to that point than to any of the neighboring points. No great differences were detected between shorebird numbers during the four tidal cycles, so data were pooled to calculated densities. Densities of each bird species (\# ind. $\mathrm{m}^{-2}$ ) were calculated for each polygon and 
merged into a single master dataset that now contained data on abiotic variables (sediment organic matter, silt, and redox), biomass of all benthic species, and bird densities for each sampling station. To approach a normal distribution for analyzed variables, organic matter content was reciprocally transformed $(y=1 / x)$, redox potential was $\log$ transformed $\left(y=\log _{10}(x)\right)$ and all other variables were square root transformed $(y=\sqrt{ } x)$.

Next, we used SEM (Amos v18) to test the spatial effects of the reefs on abiotics and the possible direct and indirect effects on the distribution of macrobenthic and bird species. For each bird species, we created default models that included all potentially important causal relationships between straight-line distance to the center of the reef (calculated in ArcGIS), directional effects that may arise from strong winds or currents (calculated in ArcGIS as the deviation of each station from the north-south axis through the center of the reef), sediment conditions (organic matter, silt fraction, and redox), macrobenthos biomass, and bird density (Figure 1). These models focus on explaining shorebird distribution from information on underlying resources. Therefore, each model only included macrobenthos species that are known prey items for that particular bird species (Table 1). Apart from modeling the effect of prey density on

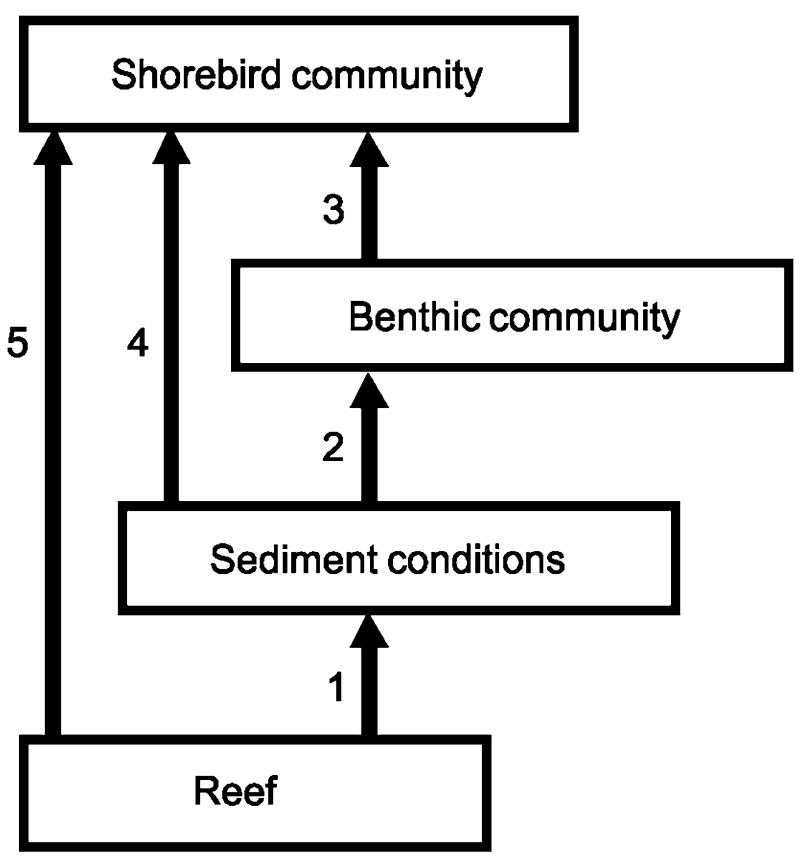

Figure 1. The conceptual path analysis model. Arrows depict direct effects of one variable (boxes) on another. Numbers represent specific mechanisms described in "Materials and Methods" and "Data Analysis". shorebird distribution, the models also tested for possible relationships between sediment variables, distance to the reef, and bird density. Sediment conditions can, directly or indirectly, affect bird distribution (Myers and others 1980; Yates and others 1993; Johnstone and Norris 2000). Furthermore, distance to the reef might influence bird distribution because birds may be attracted to these areas in anticipation of altered sediment conditions and prey densities. In summary, all four default models include (Figure 1): (1) effect of distance and direction to the reef on sediment variables, (2) the effect of sediment variables on macrobenthos, (3) effects of macrobenthos variables on bird density, (4) direct effects of sediment variables on bird density, and (5) effect of distance to the reef on bird density.

To test whether the identified relationships extended beyond the reefs themselves, we analyzed each model twice-once with all data points included (119 stations) and a second time with the stations inside the reefs excluded (111 stations). Models were analyzed with stepwise backward elimination of relations included in the default model (threshold significance for elimination: $p<0.05)$. After each elimination step, we used the $\chi^{2}$ test (probability level $>0.05$ ) to test for an adequate fit (that is, that observed data did not differ significantly from those predicted by the model), and compared the model to previous models using Akaike's Information Criterion (AIC). Unidentified models were excluded from the results. We also excluded macrobenthic species from the model if they were not correlated with the modeled bird species, whereas sediment conditions were omitted if they were not related with either macrobenthic species or bird density. Furthermore, when abiotic or benthic variables exhibited strong significant collinearity $(r>0.4)$ without one explaining the other (for example, different proxy's for sediment conditions), we only included the variable with the highest explained variation in our models. The latter was done because SEM models become notoriously unreliable when relations with very strong covariance are included (Petraitis and others 1996; Grewal and others 2004).

\section{RESUlts}

Organic matter, silt content, and redox were all highly correlated ( $r$-values for OM-silt, OM-redox, and silt-redox were $0.9,0.5$, and 0.5 , respectively) and exhibited strong spatial gradients, with organic matter and silt increasing and redox decreasing in the direction of the reef. A map overlay of organic 
Table 1. Variables Included in the Model to Test the Default Model for Each Focal Bird Species

\begin{tabular}{|c|c|c|c|c|}
\hline & \multicolumn{4}{|l|}{ Model } \\
\hline & Oystercatcher & Curlew & Bar-tailed godwit & Black- headed gull \\
\hline \multicolumn{5}{|l|}{ Prey species } \\
\hline Arenicola marina & & + & + & + \\
\hline Lanice conchilega & & + & + & \\
\hline Hediste diversicolor & + & + & + & + \\
\hline Heteromastus filiformis & & & + & \\
\hline Scoloplos armiger & & & + & + \\
\hline Cerastoderma edule & + & & & + \\
\hline Macoma balthica & + & + & + & + \\
\hline Mytilus edulis & + & & & \\
\hline Scrobicularia plana & + & + & & \\
\hline Crustaceans (Carcinus maenas and Crangon crangon) & & + & + & + \\
\hline \multicolumn{5}{|l|}{ Sediment conditions } \\
\hline Organic matter & + & + & + & + \\
\hline Silt & + & + & + & + \\
\hline Redox & + & + & + & + \\
\hline \multicolumn{5}{|l|}{ Reef builder presence } \\
\hline Distance to center of reef & + & + & + & + \\
\hline Direction to center of reef & + & + & + & + \\
\hline
\end{tabular}

General prey preferences of the four common shorebird species (Dernedde 1994; Kubetzki and Garthe 2003; Folmer and others 2010 and references therein) used in SEM are listed together with sediment conditions and distance and direction to the center of a reef. Shore crabs (C. maenus) and brown shrimps (C. crangon) were clustered as crustaceans.
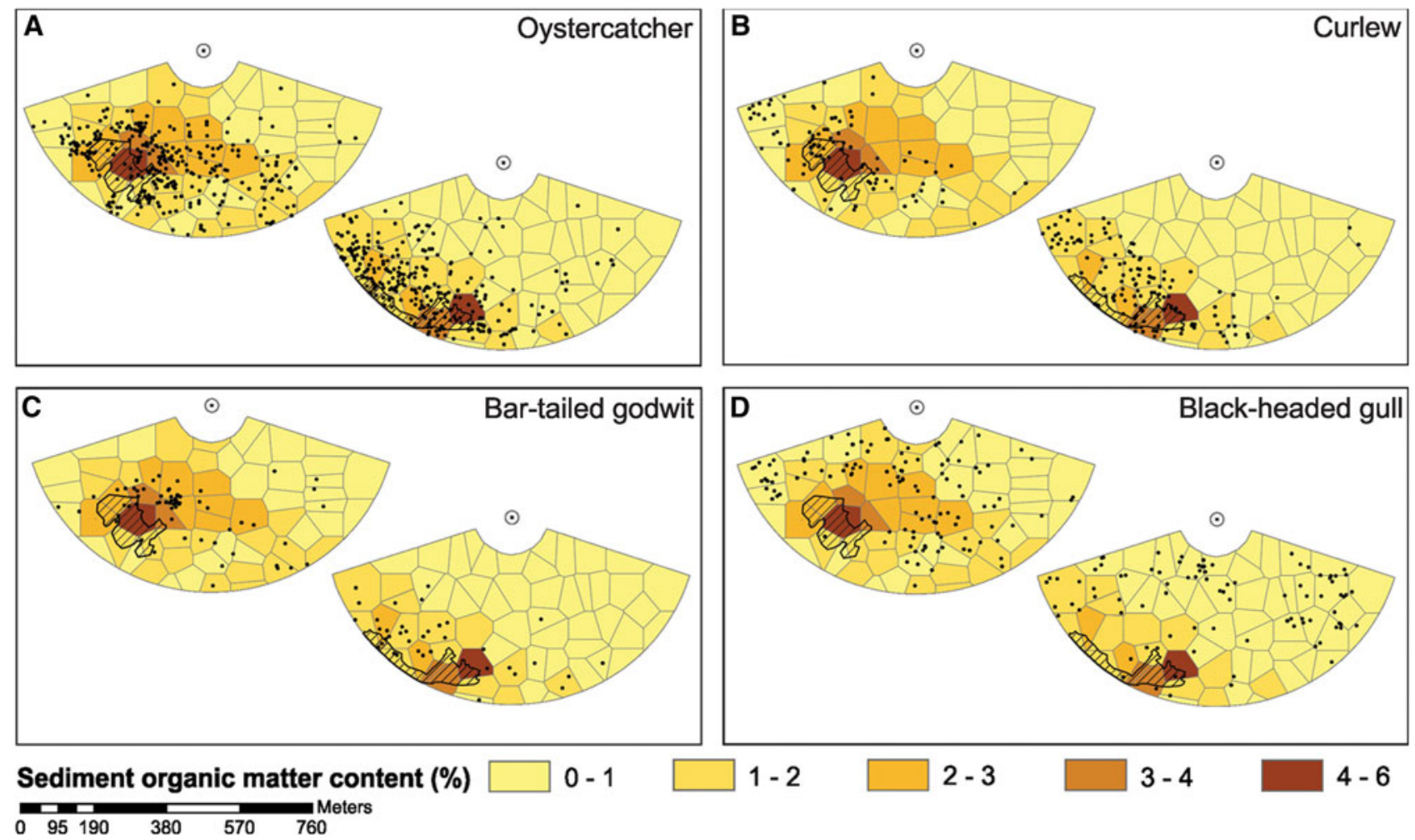

Sediment organic matter content (\%)

$0-1$ 760

Figure 2. Overview of the two reefs and their surrounding intertidal flats, showing Thiessen polygons (each polygon contains one sampling station), the position of the reefs (striped black areas), and the distribution of sediment organic matter content in relation to the distribution of $\mathbf{A}$ oystercatchers, B curlews, $\mathbf{C}$ bar-tailed godwits, and $\mathbf{D}$ black-headed gulls. Black dots represent the positions of the birds. Circles with a black dot indicate the position of the observation platforms. 


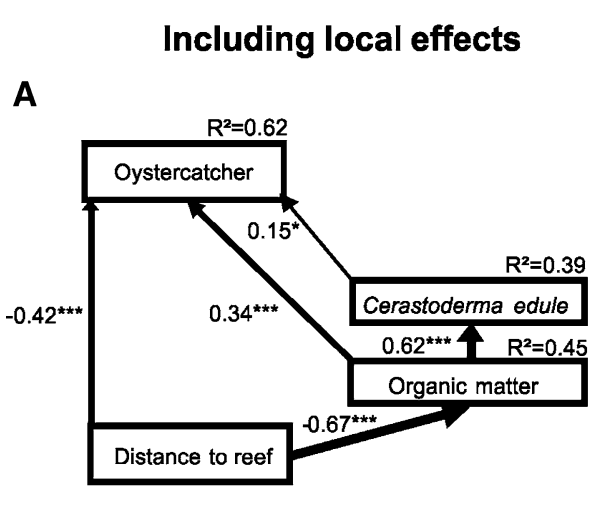

B

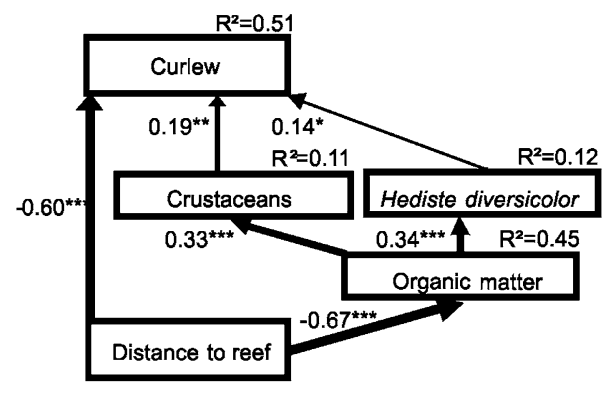

C

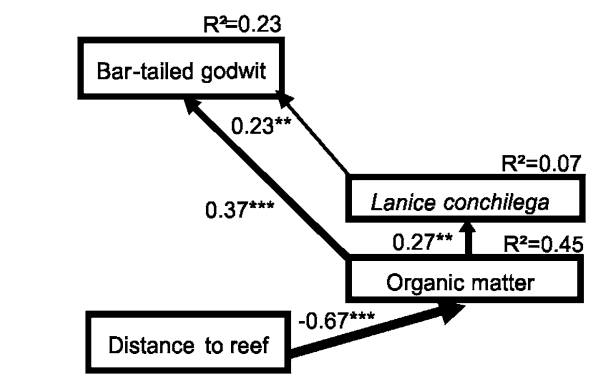

D

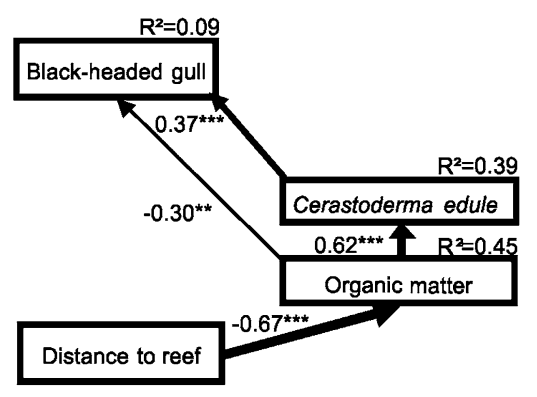

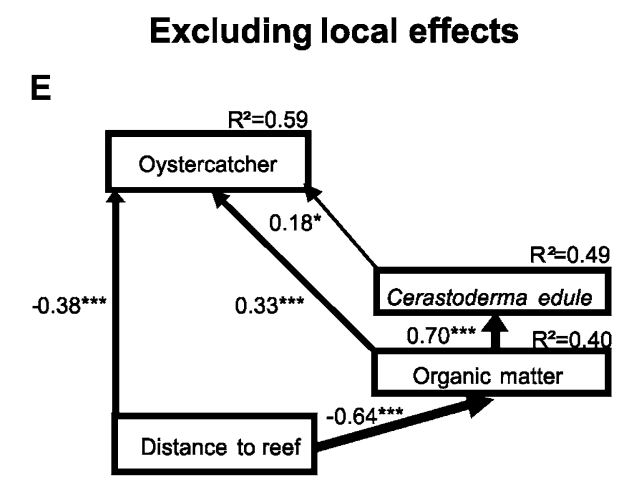

F

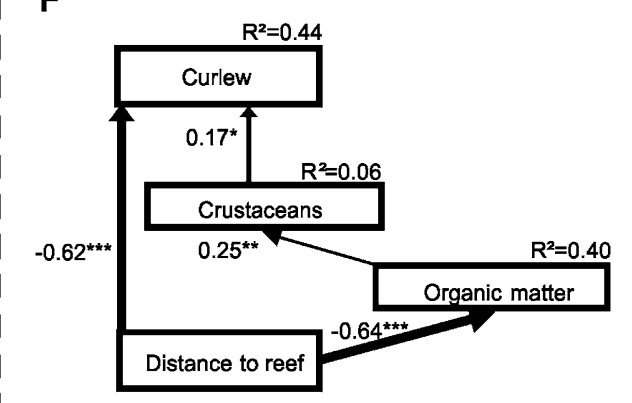

G

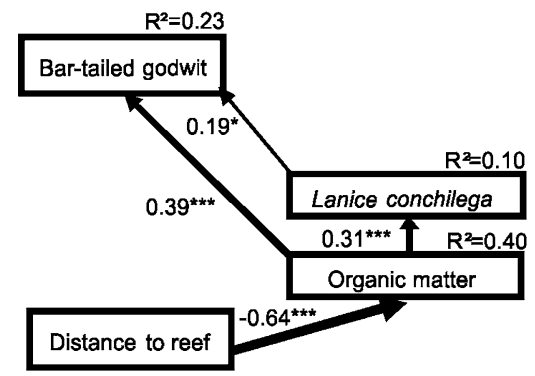

H

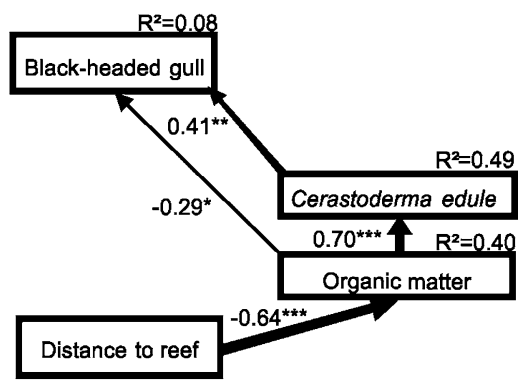

Figure 3. Diagram of the SEM results with all sampling stations for oystercatchers, curlews, bar-tailed godwits, and black-headed gulls (A-D) and the sampling stations inside the reefs excluded for the same bird species (E-H). Arrows indicate significant direct effects. The thickness line of each arrow indicates the magnitude of the standardized path coefficient, which is presented numerically next to each path. The $R^{2}$ values adjacent to the boxes represent the total variance explained by all significant predictors $\left({ }^{*} p<0.05 ;{ }^{* *} p<0.01\right.$; $* * * p<0.001)$. matter and the distribution of the four shorebird species suggest that oystercatchers, and to a lesser extent also curlews and bar-tailed godwits, tend to aggregate in these organic matter-rich areas in and around the reefs (Figure 2). In contrast, the spatial distribution by black-headed gulls appears much less affected by the presence of the reefs.
Organic matter was included as a proxy for sediment conditions in the SEM models instead of silt content or redox because of its highest explained variation $\left(R^{2 \prime}\right.$ s were $0.45,0.31$, and 0.43 , respectively). The distributions of several macrobenthic species were strongly affected by sediment organic matter, which in turn explained a significant part of 
Table 2. Model Fit Summary from SEM for the Default Model and the Final Modified Model for the Dataset with All Sampling Stations Included and for the Dataset Wherein the Sampling Stations inside the Reefs were Excluded

\begin{tabular}{|c|c|c|c|c|c|c|c|c|}
\hline & \multicolumn{2}{|c|}{ Oystercatcher } & \multicolumn{2}{|l|}{ Curlew } & \multicolumn{2}{|c|}{ Bar-tailed godwit } & \multicolumn{2}{|c|}{ Black-headed gull } \\
\hline & Default & Final & Default & Final & Default & Final & Default & Final \\
\hline \multicolumn{9}{|l|}{ All stations } \\
\hline$\chi^{2}$ & 46.383 & 0.220 & 70.176 & 3.753 & 113.654 & 0.937 & 97.784 & 0.767 \\
\hline$d f$ & 11 & 1 & 28 & 4 & 38 & 2 & 31 & 2 \\
\hline Probability level & $<0.001$ & 0.639 & $<0.001$ & 0.441 & $<0.001$ & 0.626 & $<0.001$ & 0.682 \\
\hline AIC & 96.383 & 18.220 & 146.176 & 25.753 & 193.654 & 16.937 & 167.784 & 16.767 \\
\hline \multicolumn{9}{|c|}{ Stations inside reefs excluded } \\
\hline 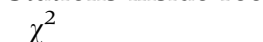 & 32.494 & 1.378 & 46.505 & 1.210 & 92.908 & 1.742 & 72.309 & 1.387 \\
\hline$d f$ & 11 & 1 & 28 & 2 & 38 & 2 & 31 & 2 \\
\hline Probability level & 0.001 & 0.240 & 0.015 & 0.546 & $<0.001$ & 0.419 & $<0.001$ & 0.500 \\
\hline AIC & 82.494 & 19.378 & 122.505 & 17.210 & 172.908 & 17.742 & 142.309 & 17.387 \\
\hline
\end{tabular}

the distribution of all four shorebirds (Figure 3; Appendix 1A, B in Supplementary material). The correlations suggest that organic matter had a positive effect on the biomass of Lanice conchilega, Hediste diversicolor, Cerastoderma edule, and crustaceans (explaining $7,12,39$, and $11 \%$ of their variance, respectively).

All default models based on the fully saturated model (Figure 1) and species-specific feeding relations (Table 1) demonstrated poor model-data fits (Table 2). After stepwise backward elimination and removal of non-significant relations, all final models demonstrated a strong fit. In contrast to the default models, final models demonstrated low Chi-square values, a probability level above 0.05 and low AIC's (Table 2; Appendix 1 in Supplementary material). After removing the sampling stations within the reefs from the dataset, all final models still had an adequate fit and the structure of the models remained nearly identical (Table 2; Figure 3). The models including the sampling stations on the reefs yielded a slightly better fit for oystercatchers, bar-tailed godwits, and blackheaded gulls, whereas the model for curlews improved after removing the reef stations.

The final models for each bird species revealed significant correlations with macrobenthic species, but also with abiotic variables. Distance to the reef, organic matter and C. edule, were significant predictors of oystercatcher density (Figure 3A, E), with the final model explaining 62 (including local effects) to 59 (excluding local effects) \% of the variance. The standardized effect of distance to the reef on oystercatcher density $(-0.417$ to -0.380$)$ was stronger than the effect of organic matter (0.338 to 0.331 ) and biomass of C. edule (0.152 to 0.179 ). For curlews (51 to $44 \%$ of the variance explained), crustaceans and distance to the reef were significant predictors for both models (Figure $3 \mathrm{~B}$ ), whereas $H$. diversicolor was dropped in the model that excluded the reef effect (Figure 3F). The standardized effect of distance to the reef on curlew density $(-0.597$ to -0.617$)$ was larger than the effect of crustacean biomass (0.195 to 0.168$)$ and biomass of $H$. diversicolor $(0.141$, only in the model which included local effects). L. conchilega and organic matter were the two significant predictors of densities of bar-tailed godwits (Figure 3C, G). The standardized effect of organic matter on bird density (0.370 to 0.386$)$ was larger than that of the biomass of L. conchilega (0.227 to 0.187$)$ and the final models both explained $23 \%$ of the observed variance. Finally, for black-headed gulls, organic matter and C. edule were significant predictors of density (Figure 3D, H). The standardized effect of C. edule on black-headed gull density (0.372 to $0.405)$ was larger than the effect of organic matter $(-0.303$ to -0.289$)$. The final models explained 9 to $8 \%$ of the variance.

\section{Discussion}

Although ecosystem engineering can determine the spatial distribution of resources (for example, Gutierrez and others 2003; van de Koppel and others 2006) and resources in turn importantly control the distribution of consumers (for example, Nachman 2006; Folmer and others 2010; Piersma 2012), the interaction between these two processes so far has rarely been examined (Olff and others 2009). Here, we demonstrate that ecosystem engineers can affect consumer-resource interactions far beyond their own physical spatial boundaries in intertidal soft-sediment systems. Reef-building 
bivalves like mussels and oysters cover a relatively small part of the intertidal mudflats of the Wadden Sea $( \pm 1 \%)$. Our results, however, imply that their ecological impact is much larger than their size may suggest.

We found strong spatial gradients of increasing sediment organic matter and silt fraction and decreasing redox potential in the direction of mixed mussel and oyster reefs, which in turn affected the distribution of benthic species. Moreover, distance from the reefs, sediment characteristics, and prey abundance simultaneously affected the distribution of the three studied species that have more or less specific prey requirements (oystercatchers, curlews, and bar-tailed godwits). This is most likely because the birds feed in the modified areas in anticipation of higher prey abundances. Black-headed gulls, the only species that did not cluster on and around the reefs, are versatile foragers with many diet options and this may explain why the reefs and the modified areas did not affect their spatial distribution. When the data points for the reefs themselves were excluded from the statistical analysis, the outcomes did not change, thus emphasizing the importance of the spatially extended effects of reefs. Only the ragworm $H$. diversicolor was excluded from the model as a predictor for the distribution of curlews. This was, however, understandable as ragworms were mostly found in muddy sediments in and around the mixed reefs.

Community structure alteration by ecosystem engineers through spatially extended habitat modification seems to occur in many different ecosystems including beaver-inhabited wetlands (Wright and others 2002) and cordgrass-inhabited cobble beaches (Bruno 2000). However, the relevance of habitat modification by ecosystem engineers on its surrounding and higher trophic levels may vary with environmental conditions. For instance, although our results show that habitat modification by reef builders can be pronounced and exceed the spatial boundaries of the reefs themselves, spatial engineering effects by the same species on rocky shores are typically more limited. In these systems, blue mussels modify environmental conditions mainly by providing structural protection for associated fauna (Thiel and Ullrich 2002; Gutierrez and others 2003). Hard substrate is already present and fine particles produced by mussels (feces and pseudofeces) are washed away by more intense hydrodynamics, resulting in more limited modifications at larger spatial scales (Thiel and Ullrich 2002). Furthermore, the effect of habitat modification by reef builders may also interact with the presence of other ecosystem engineers.
For example, the tube-worm Lanince conchilega is also considered as an ecosystem engineer in softsediment systems, as their tubes provide substrate and facilitate the deposition of fine sediments (Friedrichs and others 2000; Zühlke 2001). Because the presence of $L$. conchilega is positively correlated with the abundance and richness of the benthic community (Zühlke 2001; Callaway 2006; Godet and others 2011), L. conchilega may locally enhance the engineering effect of the reefs on the benthic and shorebird community.

In our study, SEM proved to be a useful tool for disentangling the relative importance of consumer-resource interactions and spatial habitat modification by ecosystem engineers. Using stepwise backward elimination of significant relations, we obtained models with reliable fits of multiple ecologically relevant variables. The method is correlative and therefore does not provide any direct evidence. Ideally, this method should be complemented with other, more direct approaches like smaller-scale manipulative experiments. However, before the reefs established themselves 7 years ago the study area was sandy and homogeneous, and in this respect the study reported here can be regarded as experimental (but in want of detailed description of the re-establishment situation).

In conclusion, our results indicate that consumer-resource interactions can be affected by reef builders far beyond the spatial boundaries of the reefs. This implies that these reefs have a much larger ecological impact on the intertidal community than their actual size suggests, which in turn means that loss of ecosystem engineers may result in disproportionally large consequences for biodiversity values in protected intertidal areas, like the Wadden Sea. Although the Pacific oyster is an alien species that invaded the Wadden Sea in the late 1970s (Troost 2010 and references therein), recent studies showed that oyster reefs might compensate for the large loss of mussels in 1990-1991 by replacing the ecological function of blue mussel reefs (Kochmann and others 2008; Markert and others 2009; Troost 2010). Nevertheless, the effects of Pacific oysters on the intertidal community and trophic interactions should be further investigated. Overall, our study emphasizes that conservation and restoration of reef builders should be considered a crucial step in the restoration of such systems.

\section{ACKNOWLEDGMENTS}

We thank R.C. Snoek and W. van der Heide for their help in the field. R.C. Snoek, E.J. Weerman, 
J.A. van Gils and two anonymous referees provided valuable comments on preliminary drafts of this manuscript. This study was financed by NWO grant 839.08.310 of the 'Nationaal Programma Zee-en Kustonderzoek'. Johan S Eklöf was funded by FORMAS (post-doc Grant no. 2008-839).

\section{OPEN ACCESS}

This article is distributed under the terms of the Creative Commons Attribution License which permits any use, distribution, and reproduction in any medium, provided the original author(s) and the source are credited.

\section{REFERENCES}

Bagdassarian CK, Dunham AE, Brown CG, Rauscher D. 2007. Biodiversity maintenance in food webs with regulatory environmental feedbacks. J Theor Biol 245:705-14.

Bergfeld C. 1999. Macrofaunal community pattern in an intertidal sandflat: effects of organic enrichment via biodeposition by mussel beds. First results. Senckenberg Marit 29(Suppl):23-7.

Bertness MD, Leonard GH. 1997. The role of positive interactions in communities: lessons from intertidal habitats. Ecology 78:1976-89.

Beukema JJ. 1976. Biomass and species richness of the macrobenthic animals living on the tidal flats of the Dutch Wadden Sea. Neth J Sea Res 10:236-61.

Beukema JJ, Cadee GC. 1996. Consequences of the sudden removal of nearly all mussels and cockles from the Dutch Wadden Sea. Mar Ecol 17:279-89.

Bruno JF. 2000. Facilitation of cobble beach plant communities through habitat modification by Spartina alterniflora. Ecology 81:1179-92.

Caldow RWG, Beadman HA, McGrorty S, Kaiser MJ, GossCustard JD, Mould K, Wilson A. 2003. Effects of intertidal mussel cultivation on bird assemblages. Mar Ecol Prog Ser 259:173-83

Callaway R. 2006. Tube worms promote community change. Mar Ecol Prog Ser 308:49-60.

Dernedde T. 1994. Foraging overlap of 3 gull species (Larus spp) on tidal flats in the Wadden Sea. Ophelia 6:225-38.

Dittmann S. 1990. Mussel beds-amensalism or amelioration for intertidal fauna. Helgol Meeresunters 44:335-52.

Eriksson BK, van der Heide T, van de Koppel J, Piersma T, van der Veer HW, Olff H. 2010. Major changes in the ecology of the Wadden Sea: human impacts, ecosystem engineering and sediment dynamics. Ecosystems 13:752-64.

Folmer EO, Olff H, Piersma T. 2010. How well do food distributions predict spatial distributions of shorebirds with different degrees of self-organization? J Anim Ecol 79:747-56.

Friedrichs M, Graf G, Springer B. 2000. Skimming flow induced over a simulated polychaete tube lawn at low population densities. Mar Ecol Prog Ser 192:219-28.

Godet L, Fournier J, Jaffre M, Desroy N. 2011. Influence of stability and fragmentation of a worm-reef on benthic macrofauna. Estuar Coast Shelf Sci 92:472-9.

Goss-Custard J. 1980. Competition for food and interference among waders. Ardea 68:31-52.
Goss-Custard J, Ed. 1996. The Oystercatcher: from individuals to populations. Oxford: Oxford University Press.

Goss-Custard JD, Jones RE. 1976. Diets of redshank and curlew. Bird Study 23:233-43.

Goss-Custard JD, Jones RE, Newbery PE. 1977. Ecology of Wash. 1. Distribution and diet of wading birds (Charadrii). J Appl Ecol 14:681-700.

Goudswaard PC, Kesteloo J, van Zweeden C, Fey F, van Stralen MR, Jansen J, Craeymeersch JAM. (2007). Het mosselbestand en het areaal aan mosselbanken op de droogvallende platen in de Waddenzee in het voorjaar van 2007. Institute for Marine Resources and Ecosystem Studies. Rapport C095/07.

Grewal R, Cote JA, Baumgartner H. 2004. Multicollinearity and measurement error in structural equation models: implications for theory testing. Mark Sci 23:519-29.

Gutierrez JL, Jones CG, Strayer DL, Iribarne OO. 2003. Mollusks as ecosystem engineers: the role of shell production in aquatic habitats. Oikos 101:79-90.

Hassell MP, May RM. 1974. Aggregation of predators and insect parasites and its effect on stability. J Anim Ecol 43:567-94.

Hild A, Günther CP. (1999). Ecosystem engineers: Mytilus edulis and Lanice conchilega. Dittmann S, Ed. The Wadden Sea ecosystem: stability properties and mechanisms. Berlin: Springer. pp 43-9.

Johnstone I, Norris K. 2000. The influence of sediment type on the aggregative response of oystercatchers, Haematopus ostralegus, searching for cockles, Cerastoderma edule. Oikos 89:146-54.

Jones CG, Lawton JH, Shachak M. 1994. Organisms as ecosystem engineers. Oikos 69:373-86.

Kefi S, Rietkerk M, Alados CL, Pueyo Y, Papanastasis VP, ElAich A, de Ruiter PC. 2007. Spatial vegetation patterns and imminent desertification in Mediterranean arid ecosystems. Nature 449:U213-15.

Kochmann J, Buschbaum C, Volkenborn N, Reise K. 2008. Shift from native mussels to alien oysters: differential effects of ecosystem engineers. J Exp Mar Biol Ecol 364:1-10.

Kraan C, Piersma T, Dekinga A, Koolhaas A, van der Meer J. 2007. Dredging for edible cockles (Cerastoderma edule) on intertidal flats: short-term consequences of fisher patch-choice decisions for target and non-target benthic fauna. ICES J Mar Sci 64:1735-42.

Kröncke I. 1996. Impact of biodeposition on macrofaunal communities in intertidal sandflats. Mar Ecol 17:159-74.

Kubetzki U, Garthe S. 2003. Distribution, diet and habitat selection by four sympatrically breeding gull species in the south-eastern North Sea. Mar Biol 143:199-207.

Lotze HK, Reise K, Worm B, van Beusekom J, Busch M, Ehlers A, Heinrich D, Hoffmann RC, Holm P, Jensen C, Knottnerus OS, Langhanki N, Prummel W, Vollmer M, Wolff WJ. 2005. Human transformations of the Wadden Sea ecosystem through time: a synthesis. Helgol Mar Res 59:84-95.

Markert A, Wehrmann A, Kröncke I. 2009. Recently established Crassostrea-reefs versus native Mytilus-beds: differences in ecosystem engineering affects the macrofaunal communities (Wadden Sea of Lower Saxony, southern German Bight). Biol Invasions 12:15-32.

Myers JP, Williams SL, Pitelka FA. 1980. An experimentalanalysis of prey availability for sanderling (Aves, Scolopacidae) feeding on sandy beach crustaceans. Can J Zool 58:1564-74. 
Nachman G. 2006. A functional response model of a predator population foraging in a patchy habitat. $J$ Anim Ecol 75:948-58.

Nehls G, Hertzler I, Scheiffarth G. 1997. Stable mussel Mytilus edulis beds in the Wadden Sea - they're just for the birds. Helgol Mar Res 51:361-72.

Norling P, Kautsky N. 2008. Patches of the mussel Mytilus sp. are islands of high biodiversity in subtidal sediment habitats in the Baltic Sea. Aquat Biol 4:75-87.

Olff H, Alonso D, Berg MP, Eriksson BK, Loreau M, Piersma T, Rooney N. 2009. Parallel ecological networks in ecosystems. Philos Trans R Soc B 364:1755-79.

Petersen B, Exo KM. 1999. Predation of waders and gulls on Lanice conchilega tidal flats in the Wadden Sea. Mar Ecol Prog Ser 178:229-40.

Petraitis PS, Dunham AE, Niewiarowski PH. 1996. Inferring multiple causality: the limitations of path analysis. Funct Ecol 10:421-31.

Piersma T. 1985. Dispersion during foraging, and prey choice, of waders in the Nakdong Estuary, South Korea. Wader Study Group Bull 45:32-3.

Piersma T. (2012). What is habitat quality? Dissecting a research portfolio on shorebirds. Fuller R, Ed. Birds and habitat: relationships in changing landscapes. Cambridge: Cambridge University Press.

Piersma T, Koolhaas A, Dekinga A, Beukema JJ, Dekker R, Essink K. 2001. Long-term indirect effects of mechanical cockledredging on intertidal bivalve stocks in the Wadden Sea. J Appl Ecol 38:976-90.

Rietkerk M, Dekker SC, de Ruiter PC, van de Koppel J. 2004. Self-organized patchiness and catastrophic shifts in ecosystems. Science 305:1926-9.

Scanlon TM, Caylor KK, Levin SA, Rodriguez-Iturbe I. 2007. Positive feedbacks promote power-law clustering of Kalahari vegetation. Nature 449:209-212.

Scheiffarth G. 2001. The diet of bar-tailed godwits Limosa lapponica in the Wadden Sea: combining visual observations and faeces analyses. Ardea 89:481-94.

Thiel M, Ullrich N. 2002. Hard rock versus soft bottom: the fauna associated with intertidal mussel beds on hard bottoms along the coast of Chile, and considerations on the functional role of mussel beds. Helgol Mar Res 56:21-30.

Thiessen AH. 1911. Climatological data for July, 1911. Mon Weather Rev 39:1082-4.

Troost K. 2010. Causes and effects of a highly successful marine invasion: case-study of the introduced Pacific oyster Crassostrea gigas in continental NW European estuaries. J Sea Res 64:145-65.

van de Kam J, Ens B, Piersma T, Zwarts L. 2004. Shorebirds: an illustrated behavioural ecology. Utrecht: KNNV Publishers.

van de Koppel J, Altieri AH, Silliman BS, Bruno JF, Bertness MD. 2006. Scale-dependent interactions and community structure on cobble beaches. Ecol Lett 9:45-50.

van de Pol M. (2006). State-dependent life-history strategies: a long-term study on oystercatchers. PhD thesis, University of Groningen, pp 13-42.

van der Heide T, van der Zee EM, Donadi S, Eklöf JS, Eriksson BK, Olff H, Piersma T, van der Heide W. 2011. A simple and low cost method to estimate spatial positions of shorebirds: the Telescope-Mounted Angulator. J Field Ornithol 82:80-7.

van der Heide T, van Nes EH, Geerling GW, Smolders AJP, Bouma TJ, van Katwijk MM. 2007. Positive feedbacks in seagrass ecosystems-implications for success in conservation and restoration. Ecosystems 10:1311-22.

van Gils JA, Spaans B, Dekinga A, Piersma T. 2006. Foraging in a tidally structured environment by red knots (Calidris canutus): ideal, but not free. Ecology 87:1189-202.

Wright JP, Jones CG, Flecker AS. 2002. An ecosystem engineer, the beaver, increases species richness at the landscape scale. Oecologia 132:96-101.

Yates MG, Goss-Custard JD, McGrorty S, Lakhani KH, Durell S, Clarke RT, Rispin WE, Moy I, Yates T, Plant RA, Frost AJ. 1993. Sediment characteristics, invertebrate densities and shorebird densities on the inner banks of the Wash. J Appl Ecol 30:599-614.

Zühlke R. 2001. Polychaete tubes create ephemeral community patterns: Lanice conchilega (Pallas, 1766) associations studied over six years. J Sea Res 46:261-72. 